\title{
Alianças e coalizões internacionais do governo Lula: o Ibas e o G-20
}

\author{
Alliances and Coalitions in the Lula Administration: \\ An analyisis of Ibsa and G20
}

MARCELO FERNANDES DE OLIVEIRA*

Rev. Bras. Polít. Int. 8 (2): 55-69 [2005]

\section{Introdução}

Nos últimos anos, o ambiente internacional tornou-se mais turbulento e tenso, inaugurando um período de transformaçōes nas orientações políticas e econômicas prevalecentes nos anos 90. Do lado político, após a emergência da administração G. W. Bush e dos atentados terroristas, os Estados Unidos passaram a acentuar o viés unilateral do exercício da sua política externa. Evidenciaram, inclusive, a disposição em utilizar o "ataque preventivo" para evitar qualquer ameaça à supremacia político-militar global norte-americana.

$\mathrm{Na}$ órbita econômica, a experiência da Argentina demonstrou aos países em desenvolvimento e PMDR - Países de Menor Desenvolvimento Relativo que a adesão ao discurso hegemônico liberal de integração aos mercados globais preconizado pelos países desenvolvidos e pelos organismos internacionais, tais como FMI e Banco Mundial, não garante desenvolvimento econômico e social, nem apoio nos momentos de crise. Pelo contrário, os próprios países tendem a ser responsabilizados por seguirem o receituário neoliberal do mainstream internacional.

Em suma, a agenda econômica dominante no fim do século passado está perdendo proeminência vis-à-vis a agenda da segurança, o que tornou inviável a continuidade da estratégia de inserção internacional baseada na premissa da autonomia pela integração do governo Fernando Henrique Cardoso. Em outras palavras, os novos constrangimentos sistêmicos internacionais demandaram a reformulação da estratégia de inserção internacional do Brasil. Nessa direção, já quase no fim de seu mandato, a diplomacia do governo Cardoso intensificou relações e estabeleceu coalizões na lógica da geometria variável de poder com

* Doutor em Ciência Política pela USP e Pesquisador do Centro de Estudos de Cultura Contemporânea

- CEDEC (marfern@terra.com.br). 
países em desenvolvimento na OMC - Organização Mundial de Comércio, tais como Índia e África do Sul durante o contencioso das patentes farmacêuticas contra os Estados Unidos. Contudo, a derrota eleitoral da coalizão política liderada por Cardoso para Lula em 2002 não lhe permitiu colher os frutos dessa empreitada internacional, até então relegada ao segundo plano durante seus dois mandatos.

A diplomacia brasileira sob o governo Lula aprofundou a correção de rota iniciada em fins do segundo mandato de Cardoso. Imediatamente após suas posses, Lula e Amorim declararam ser necessário reinterpretar as premissas clássicas da política externa brasileira, dando a elas um novo sentido. $\mathrm{O}$ objetivo seria garantir a sustentação de uma estratégia de inserção internacional do país diferente daquela presente na maior parte do governo Cardoso e que fosse mais adequada às demandas das novas elites econômicas, das coalizões sociais e políticas no poder, da percepção do papel a ser ocupado pelo Estado brasileiro no mundo e dos constrangimentos internacionais à inserção periférica dos países em desenvolvimento.

Nesta perspectiva, a diplomacia do governo Lula passou a considerar o multilateralismo como um movimento amplo de desconcentração e de novas regulamentações do poder no sistema internacional, de modo que fossem mais favoráveis aos países em desenvolvimento. Estaria ocorrendo um “(...) redesenho da balança de poder global, a qual vem criando novas possibilidades e brechas de inclusão de novos atores e projetos de reorganização do sistema de Estados e dos valores no seio da comunidade internacional" (Saraiva, 2005). Caberia ao país voltar a desenvolver uma política externa mais heterodoxa, conceitualmente estruturada em torno dos temas do "desenvolvimento como um valor universal e o acesso das grandes massas populacionais do globo aos padrões do bem estar e da cidadania" (Saraiva, 2005).

Em síntese, a política externa brasileira deve ser eficaz na defesa de condições mais adequadas aos países em desenvolvimento, para que elaborem políticas públicas que permitam gerar crescimento econômico, consolidar a democracia e, por conseqüência, combater a pobreza, a exclusão social e a fome. Enfim, caberia consolidar o consenso global de um multilateralismo compatível com os objetivos de desenvolvimento. A diplomacia do governo Lula vem recuperando, pelo menos em parte, as tradiçóes da agenda da Política Externa Independente e, ainda que com modificações significativas, a do Pragmatismo Responsável e Ecumênico do governo Geisel.

Portanto, a origem do protagonismo internacional brasileiro na atualidade parece ter sua inspiração nessa tradição da política externa brasileira, caracterizada como nacional-desenvolvimentista. Seus desdobramentos práticos estão consubstanciados na formação do Ibas - Fórum de Diálogo Índia, Brasil e África do Sul; na criação do G-20 - Grupo de países em desenvolvimento criado na fase final de preparação da V Conferência Ministerial da OMC; na 
aproximação com países africanos e árabes; na participação no G-4 - Grupo composto por Alemanha, Brasil, Índia e Japão - em busca da reforma no Conselho de Segurança da ONU e das suas respectivas admissóes nele como membros permanentes; na revalorização da inserção regional, inclusive ao se dispor a arcar com os custos do exercício da sua liderança, especificamente, no Mercosul - Mercado Comum do Sul - e na América do Sul, além de incentivar seus parceiros em desenvolvimento a também incorporarem a dinâmica regional às suas respectivas política externa, visando consolidar seus papéis de relevância regional. A missão de paz da ONU conduzida pelo Brasil no Haiti é ilustrativa dessa agenda política.

Pode-se notar nesse protagonismo internacional do governo Lula a clara intenção de ressuscitar a questão do desenvolvimento e a recuperação da clivagem Norte/Sul na política internacional em benefício das demandas dos países em desenvolvimento. Com base nessa constatação cabe-nos indagar se as estratégias internacionais e o diálogo Sul-Sul presente na retórica e na ação da política externa do governo Lula representam alianças duradouras ou coalizóes efêmeras nas relações internacionais contemporâneas entre os países em desenvolvimento.

Buscaremos responder essa questão mapeando o processo de construção de alianças e coalizões entre o Brasil e seus parceiros emergentes, especificamente o estabelecimento do Ibas como desdobramento do contencioso das patentes contra os Estados Unidos e da reunião do G-8 em Evian em 2003, e o papel do G-20 em prol da liberalização do comércio agrícola internacional nos contenciosos do algodão contra os EUA e do açúcar contra a UE - União Européia - e, particularmente, durante a V Conferência de Cancun da OMC.

\section{O contencioso das patentes farmacêuticas na OMC: a origem do lbas}

Em 1997, a diplomacia comercial dos Estados Unidos havia buscado revogar a legislação sul-africana Medicines and Related Substances Control Act Amendments que permitia o licenciamento compulsório e a importação paralela de medicamentos mais baratos de terceiros países, principalmente da Índia, sem a autorização do detentor da patente (Rosenberg, 2001). Os Estados Unidos ameaçaram suspender a ajuda econômica e, em abril de 1999, inseriram a África do Sul na lista de observações (watch list) da Special 301 (Love, 1999; Roffe, 2004).

Essa posição só foi revista quando o candidato $\mathrm{Al}$ Gore passou a receber pressão de ONGs internacionais, bem como perdeu o apoio da comunidade de afro-descendentes norte-americana à plataforma eleitoral democrata durante a campanha de 2000 . Esta comunidade decidiu votar no candidato independente Ralph Nader porque ele foi favorável ao licenciamento compulsório de patentes de remédios contra o HIV para a África do Sul. Para evitar maiores custos eleitorais, em dezembro de 1999, o governo dos Estados 
Unidos retirou a África do Sul da lista de observaçôes (watch list) da Special 301 (Cepaluni, 2004).

Essa atitude desagradou a indústria farmacêutica que ampliou suas doações de recursos para a campanha do republicano G. W. Bush (US\$ 18,3 milhões - 69\%) vis-à-vis à campanha do democrata Al Gore (US\$ 8,3 milhōes - 31\%) (Center for Responsive Politics, 2000). Como "gratidão", G. W. Bush, logo no início de seu mandato, questionou o artigo 68 da lei brasileira 9279/96, que previa a possibilidade do uso de licença compulsória em casos de emergência de saúde pública. Segundo o USTR, esse artigo não estava de acordo com o TRIPS. Logo, o Brasil foi inserido na Section 301 Watch List, acusado de ser "desrespeitador de patentes" (patent-miscreant).

Em 30 de maio de 2000, os Estados Unidos entraram com pedido de consultas junto ao governo brasileiro na OMC. Não satisfeitos com a resposta brasileira, em janeiro de 2001, entraram com pedido de estabelecimento de panel no Órgão de Solução de Controvérsias da OMC, apresentando a mesma queixa e afirmando que as consultas não trouxeram os resultados esperados, tampouco a solução para o conflito.

A estratégia de defesa brasileira nesse contencioso foi mobilizar uma série de atores internacionais relevantes para a configuração de climas de opinião pública globais favoráveis às demandas domésticas de países em desenvolvimento e Países de Menor Desenvolvimento Relativo (PMDR). Desde o início, a diplomacia brasileira enfatizou que a questão era de grande relevância social e econômica, pois o direito de override 1 significava a possibilidade do aumento da disponibilidade de drogas genéricas para o tratamento de doentes de Aids no Brasil. Os preços exorbitantes praticados pela indústria farmacêutica norte-americana estavam impossibilitando a continuação do atendimento gratuito aos portadores da doença no país. O laboratório Merck reduziu o preço do anti-retroviral efavirezn, bem como o laboratório Roche também se comprometeu a baixar o preço do nelfinavir em $40 \%$. Contudo, outras empresas recusaram-se a negociar.

Em contrapartida o governo brasileiro, em março de 2001, alertou que poderia fornecer licenças compulsórias para a produção local dos medicamentos pelo Far-Manguinhos, caso as empresas não reduzissem ainda mais seus preços. Ao ser ignorado, o governo brasileiro declarou que a única prioridade tanto do governo norte-americano quanto das suas empresas era garantir a manutenção dos lucros, fazendo-os prevalecer sobre o bem-estar dos brasileiros, ou seja, sobre o direito universal à saúde garantida pela Constituição brasileira, assim como, do ponto de vista ético-moral, sobre a população de outros países pobres,

\footnotetext{
${ }^{1}$ Segundo essa premissa, o Brasil deveria ampliar o poder de controle sobre o seu destino e resolver seus problemas através da adesão ativa à elaboração das normas e das pautas de conduta da gestão da ordem mundial, buscando consolidar o multilateralismo na política internacional (Vigevani e Oliveira, 2003).
} 
tais como a África do Sul e seus vizinhos. Simultaneamente, para garantir que a ameaça fosse factível, o governo brasileiro autorizou o Far-Manguinhos a importar da Índia os princípios ativos para iniciar os testes e as pesquisas necessárias à viabilização da produção local desses medicamentos.

A Índia ainda está usufruindo as benesses da "regra de transição" que possibilitou aos países em desenvolvimento aderirem e implementarem os "princípios, normas, regras e procedimentos" do Acordo TRIPS - Acordo sobre Aspectos de Direito de Propriedade Intelectual Relacionados ao Comércio somente depois de $2005^{2}$. Até o momento, sua lei de propriedade intelectual - Indian Patent Act - garante a proteção de procedimentos, mas não da produção de remédios. Essa condição permitiu a Índia desenvolver um pólo industrial farmacêutico para a comercialização de medicamentos genéricos anti-retrovirais essenciais no tratamento da Aids por meio de estratégias de engenharia reversa. Suas principais empresas - a Cipla, a Ranbaxy, a Hetero, a Aurodindo e a Cadila - são capazes de concorrer com as grandes corporações transnacionais, oferecendo produtos a preços reduzidos com qualidade semelhante.

A Cipla, por exemplo, disponibilizou o "coquetel" anti-Aids (terapia tripla) a US\$ 350 às ONGs de direitos humanos envolvidas com a prevenção e o tratamento dos doentes de HIV. A Hetero passou a comercializar o mesmo produto por US\$347. A Ranbaxy propôs vender o coquetel por US\$295 sob as mesmas condições. Os preços praticados para os governos giravam em torno de US\$ 600. Como conseqüência, o preço do tratamento foi reduzido em mais de $78 \%$ em pouco menos de dois anos (Guennif e Mfuka, 2004). Além disso, essas empresas lucraram com a importação paralela de princípios ativos para a fabricação de certos medicamentos genéricos contra a Aids, tornando a Índia um aliado essencial na coalizão dos países em desenvolvimento.

Os negociadores brasileiros, ao perceberem a potencialidade dessa coalizão e das oportunidades abertas pela lógica de geometria variável de poder na $\mathrm{OMC}$, reforçaram sua argumentação ao elaborarem a premissa humanitária, o slogan de que o bem público deve prevalecer sobre o lucro. Dessa forma, legitimou a estratégia de defesa do país, além de obter simpatia internacional de Quênia, Moçambique, Zimbábue, Ruanda, dentre outros, todos interessados em transferência de tecnologia e cooperação técnica internacional do Brasil para o tratamento dos seus doentes de Aids, bem como de remédios mais baratos da Índia. Além, é claro, da África do Sul (país que sofre com epidemia de HIV/Aids e, como o Brasil, não possui recursos financeiros para garantir tratamento gratuito adequado a todos que necessitam) e da Índia (país com tecnologia avançada na produção de genéricos e medicamentos em geral, ocupando papel importante no comércio internacional de medicamentos, interessada em vender genéricos), como vimos.

2 Passar por cima da exclusividade de comercialização e/ou produção (market exclusivity) de medicamentos usados no tratamento de Aids. 
$\mathrm{O}$ argumento brasileiro convenceu a opiniāo pública internacional e as comunidades epistêmicas $^{3,4}$ (Haas, 1992), as quais tornaram-se essenciais para a "vitória" da coalizão porque defenderam o direito do Brasil, dos países em desenvolvimento e dos PMDR ao acesso a medicamentos. Entre os atores principais, estavam ONGs como Médecins Sans Frontièrs, Health GAP e Oxfam, envolvidas com os temas de saúde pública e de direitos humanos, e até mesmo a ONU - Organização das Nações Unidas - por meio do Unaids - Programa Conjunto das Naçôes Unidas sobre HIV/Aids - e a OMS - Organização Mundial da Saúde - (Oxfam, 2003). Parcelas consideráveis da sociedade civil norte-americana apoiaram a coalizão. Essas comunidades estavam convencidas de que o Brasil e seus parceiros deveriam ter o direito de fornecer medicamentos à sua população a despeito da redução dos lucros da indústria farmacêutica. Nessa direção, muitos desses atores adquiriam o coquetel anti-HIV na Índia, a preços bem menores, como vimos acima, e doavam aos governos africanos mais pobres.

Os resultados dessas mobilizações foram bastante positivos para os países em desenvolvimento. Os negociadores dos Estados Unidos optaram por retirar a queixa, recuando na sua posição intransigente de defesa de direitos de propriedade intelectual, e decidiram negociar com o Brasil e seus aliados uma solução para o problema que atendesse aos interesses de todos. Logo, podemos afirmar que essa experiência legou, pelo menos, dois frutos permanentes: a) aprendizado de como utilizar as estruturas globais de poder em prol dos interesses brasileiros e dos seus parceiros, auxiliando na construção de bens públicos globais, a serem utilizados por outros países menos favorecidos contra as práticas comerciais desleais, sobretudo, dos países desenvolvidos e b) serviu como pano de fundo para o relançamento de alianças Sul-Sul na política internacional.

Em suma, vale ressaltar que o contencioso das patentes serviu como modelo, como um ensaio bem sucedido da potencialidade de coalizões SulSul para a ampliação da participação unida dos países em desenvolvimento e dos PMDR nas grandes questões internacionais. Entretanto, a diplomacia brasileira do governo Cardoso nem buscou consolida-lo nem teve outras iniciativas similares. Isso ocorreu somente mais tarde, já no governo Lula, no bojo dos debates da Cúpula do G-8, em Evian, em junho de 2003.

Nessa ocasião, G. W. Bush enfatizou a necessidade da cooperação internacional nas questôes relativas ao desenvolvimento e ao comércio, pois, "Em longo prazo, reforçamos nossa segurança ao ajudar a disseminar a liberdade

\footnotetext{
${ }^{3}$ Vale ressaltar que há uma lei em tramitação na Índia adequando sua legislação de propriedade intelectual ao TRIPS.

${ }^{4}$ Comunidades epistêmicas podem ser consideradas como “(...) canais através dos quais novas idéias circulam de sociedades a governos, bem como de país para país” (Haas, 1992:27). Ou então, “(...) uma rede de profissionais com perícia reconhecida e competência em um domínio específico e com pretensão oficial de conhecimentos relevantes a políticas dentro daquele domínio ou área" (Haas, 1992:3) (Tradução livre).
} 
e aliviar o sofrimento. E isso estabelece uma ampla agenda para as nações dos dois lados do Atlântico" (Bush, 2005). Bush estabeleceu prioridades globais por meio da proposta Conta do Desafio do Milênio (MCA), a qual pretendia “(...) recompensar as políticas econômicas que funcionam - governança macroeconômica sólida, um sistema de regulamentação eficiente, abertura comercial e um ambiente saudável para os investimentos" (Wayne, 2005). A iniciativa objetivava estimular o crescimento econômico, combater o terrorismo, impedir a proliferação de armas de destruição em massa e, principalmente, promover a prosperidade no mundo em desenvolvimento.

Os países desenvolvidos se comprometeram ainda em elaborar mecanismos para dar maiores oportunidades aos países pobres no comércio internacional. Passariam a promover programas e acordos comerciais preferenciais mais favoráveis aos seus produtos, ampliar oportunidades de mercado e estimular à integração e o comércio regional entre os países em desenvolvimento. Além disso, se comprometeram a retirar barreiras procedimentais que impedem a liberalização comercial multilateral de produtos agrícolas, conforme a agenda de Doha.

A diplomacia brasileira aproveitou essa oportunidade para convocar uma Reunião Trilateral de Chanceleres do Brasil, da África do Sul e da Índia, que foi realizada na cidade de Brasília, no dia 6 de junho de 2003. Nessa ocasião, diante das propostas do G-8, da experiência acumulada com o contencioso das patentes e das suas similaridades e convergências políticas em outros fóruns internacionais, foi assinada a Declaração de Brasília, a qual estabeleceu uma aliança permanente entre África do Sul, Índia e Brasil: o Ibas.

Entre outros propósitos, essa parceria visa a consolidar um bloco trilateral Sul-Sul para o fortalecimento da capacidade política nas negociações comerciais internacionais desses países na OMC frente aos partners desenvolvidos. Ao mesmo tempo, busca ainda uma reforma da ONU, que torne a instituição mais democrática. $\mathrm{O}$ fator essencial nessa perspectiva é a incorporação de novos países no Conselho de Segurança, os quais devem representar efetivamente a multiplicidade da comunidade global - Brasil, Índia e África do Sul se consideram como tais. Além disso, a redução da pobreza deve ser levada a sério como meio para aumentar a paz e a estabilidade internacional. Por fim, o Ibas visa ainda a desenvolver e a intercambiar cooperação técnica nas áreas de transporte, energia, infra-estrutura, defesa e missões de paz, comércio e investimento, pequenas empresas e criação de emprego, ciência e tecnologia de informação, educação, saúde (direitos de propriedade intelectual, medicina tradicional, pesquisas epidemiológicas, vacinas, desenvolvimento de produtos), bem como a criação de um fundo para alívio da pobreza e da fome (Ibas, 2005). Esses objetivos estão em convergência com as decisões tomadas durante a Cúpula do G-8 em Evian.

Apesar de ser um marco do retorno de estratégias e alianças Sul-Sul, debilitadas durante a discussão do Gatt - Acordo Geral sobre Tarifas e Comércio 
-, o Ibas possui debilidades, as quais devem ser corrigidas para que haja a consolidação de uma aliança duradoura. A principal delas deriva da sua agenda bastante ampla e ambiciosa, como vimos acima. Com o tempo, a ausência de avanços e resultados concretos, tais como os obtidos no contencioso das patentes dos remédios anti-HIV, poderá comprometer a credibilidade da iniciativa.

Entre outros fatores, a proposta da Aliança Africana para a reforma da ONU praticamente inviabilizou os objetivos do G-4. Ela pode ser considerada a primeira externalidade negativa do Ibas. Isso porque o fundo para o alívio da pobreza e da fome criado pelo Ibas direcionado ao continente africano não serviu aos propósitos de mitigar o receio dos países da Aliança Africana de que a África do Sul não se tornaria uma ameaça hegemônica regional no caso de ser membro permanente do Conselho de Segurança. As potencialidades e as oportunidades de fluxos comerciais entre os países membros do Ibas também são reduzidas. Há pouca complementaridade e sinergia entre eles, por um lado, e por outro, concorrência em setores importantes para cada uma das economias no mercado mundial. Portanto, o Ibas, nesse momento, parece ser bastante abstrato, ainda que tenha sua importância política. Todavia, a médio e em longo prazo, essa aliança pode se tornar relevante para o Brasil. Na medida em que poderá se constituir em porta de entrada dos produtos brasileiros na África e, principalmente na Ásia.

\section{A questão dos subsídios agrícolas e a Conferência de Cancún: o G-20 em ação}

A V Conferência Ministerial da OMC em Cancún terminou sem consenso. Nas palavras do diplomata queniano George Ogwar "A reunião entrou em colapso" (Velasco e Cruz, 2005). Isso ocorreu porque, por um lado, os países desenvolvidos insistiram na necessidade de aprofundar as negociações em torno dos temas de Cingapura. Por outro lado, os países em desenvolvimento e os PMDR condicionaram esse aprofundamento à eliminação dos subsídios e à liberalização do comércio agrícola internacional.

Segundo Zoelick (2003), a culpa do fracasso deveu-se à ação do Brasil e seus aliados - principalmente da Índia - que preferiram adotar a retórica da resistência como tática contra os países desenvolvidos na questão agrícola, para encobrir suas barreiras comerciais nos temas de Cingapura ( $O$ Estado de São Paulo, 2004; Folha de São Paulo, 2004-a).

Diferentemente, para Amorim (2003), Cancún "marca um ponto de inflexão na dinâmica interna da $[\mathrm{OMC}]$ onde, tradicionalmente, o que era decidido pelas grandes potências comerciais era visto como o consenso inevitável. (...) As postulações da maior parte da humanidade não puderam ser ignoradas. [A partir de então] as negociações se processarão de maneira mais equilibrada e menos unilateral". Isso ocorreu "Graças a um esforço conjunto de 22 países 
em desenvolvimento, coordenados pelo Brasil, do qual participaram países grandes e pequenos de três continentes" (Amorim, 2003).

Em convergência com Amorim (2003), Arun Jaitley, Ministro do Comércio e Indústria da Índia, declarou que India did not yield on any issue at Cancun and engaged pro-actively in the negotiations. The fact that we brought the concerns of developing countries to the center stage reflects the success of Cancun (India Infoline News, 2003). Para Anand Mahindra, presidente da Confederação Indiana das Indústrias Cancun represents a turning point in trade negotiations. These will never be the same again. The developing countries are now a force to reckon with, India led by Commerce Minister Arun Jaitley was a major force in bringing together many countries on a common platform (Rediff, 2003). $\mathrm{O}$ Ministro da África do Sul, presente na Conferência de Cancún, salientou que "nós estamos muito bem preparados. Fizemos propostas muito concretas para a agricultura. Nós todos estamos muito impressionados em nossos países pela capacidade que temos. (...) Foi a primeira vez que nós pudemos sentar de igual para igual" com os países desenvolvidos (O Estado de São Paulo, 2003).

Essas declarações indicam que a Conferência de Cancún pode ter representado o momento inaugural da proposta do governo Lula de adensamento do diálogo e das parcerias Sul-Sul em busca de uma mudança da geografia comercial e política do mundo favorável aos países em desenvolvimento e aos PMDR. A convergência entre Brasil, Índia e China permitiu que esses países liderassem uma coalizão, a qual, mais tarde, ficou conhecida como G-20 e concentrou sua atuação em agricultura: tema central da Agenda de Desenvolvimento de Doha.

A articulação do G-20 na Conferência de Cancún parece ter garantido um novo papel aos países em desenvolvimento nas discussões sobre a liberalização do comércio internacional, especificamente o agrícola: o papel de serem uma ameaça de veto unificada e principalmente qualificada ao desempenhar um papel pró-ativo à solução da problemática. Isso porque representou uma aliança de países de três continentes, a qual abriga $60 \%$ da população rural, $12 \%$ da produção agrícola, $26 \%$ das exportaçóes e $18 \%$ das importações mundiais. Constituem os mais dinâmicos produtores e os mercados agrícolas mais promissores. O papel desempenhado pela liderança foi importante, pois demonstrou sua capacidade em manter coesos interesses diferentes, mas que convergiram diante da ameaça iminente de suas demandas não serem contempladas na V Conferência. A ausência de sinais de fratura e/ ou defecção entre os líderes garantiu credibilidade à ameaça de retaliação do grupo e, simultaneamente, deixou evidentes as possibilidades de ganhos advindas daí aos países menores. Outra prova da importância do papel da liderança foi a participação do Brasil no encontro em Londres para a discussão dos rumos a serem tomados nas próximas negociações comerciais.

Mais importante foi o fato desses países abandonarem a agenda de veto reativa que lhes desqualificavam constantemente durante as discussões e 
apresentarem uma agenda pró-ativa, com capacidade técnica substantiva alicerçada em informações apuradas e convincentes que lhes permitiram, mais do que dizer "não", oferecer e propor alternativas viáveis ao impasse. Claramente, esses países foram capazes de renovar suas estratégias ao combinarem a lógica das coalizões de bloco com coalizões temáticas. Ou seja, ao invés de negociarem apenas em torno de fatores ideacionais e identitários, como ocorria com as coalizões de bloco do passado, tais como o movimento dos não-alinhados, o G-20 negociou também como uma coalizão temática em torno de questōes instrumentais. Isso proporcionou a oportunidade da emergência de coalizóes de novo tipo, de terceira geração, as quais tendem a permitir que países em desenvolvimento recuperem a clivagem Norte/Sul na política internacional, atuem como coalizão de bloco, mas, ao mesmo tempo, estabeleçam coalizões temáticas, apropriando-se instrumentalmente com grande capacidade técnica da agenda pró-livre-comércio dos países desenvolvidos para abrir seus mercados agrícolas. Em complemento, essa estratégia incorpora valores éticos e morais que acabam se traduzindo em apoio efetivo de novos atores internacionais, tais como ONGs, os quais possuem a capacidade de moldar agendas globais e influenciar efetivamente a opinião pública. Segundo Held (2004), seria uma estratégia cosmopolita preocupada com questões de justiça social, bem como a democratização da política internacional.

Ao discursar para os representantes de países do G-20, de acordo com a idéia de configurar uma nova geografia do comércio mundial, Lula (2004) aproveitou a oportunidade para afirmar que esse novo tipo de articulação deveria inspirar novas ações também em outros tabuleiros, além dos fóruns internacionais já consolidados como a OMC e a ONU, para ampliar “(...) o nosso intercâmbio recíproco, especialmente para a intensificação do comércio Sul-Sul” (G-20, 2005).

Segundo Veiga (2005), o G-20 pode gerar externalidades positivas associadas a iniciativas nem sempre comerciais entre países em desenvolvimento. $\mathrm{O}$ “(...) componente comercial das relações bilaterais pode, inclusive, não desempenhar o papel central, embora a própria iniciativa possa gerar externalidades positivas para o país em foros multilaterais" (Veiga, 2005, p. 5) obtendo ganhos, ainda que parciais, relevantes para os interesses setoriais de países que, até pouco tempo, tinham apenas a perder nas negociações comerciais internacionais.

Por exemplo, no campo do comércio multilateral, as estratégias, as coalizões e as alianças do Brasil e dos seus parceiros em desenvolvimento vêm realizando a defesa do livre-comércio dos produtos e a redução dos altos subsídios agrícolas que protegem os mercados dos países desenvolvidos, de acordo com a demanda das elites econômicas nacionais desse setor. Segundo Veiga (2005, p. 7) “(...) a estratégia governamental internalizou e deu prioridade às demandas de liberalização dos mercados agrícolas, que traduzem essencialmente um processo de transformação estrutural da economia brasileira expresso na emergência de 
um agribusiness voltado para a exportação e altamente competitivo". Os contenciosos do algodão contra os EUA e do açúcar contra a UE na OMC são partes dessa estratégia, pois podem significar um novo elemento na configuração do regime de comércio internacional. Eles poderão ter impacto direto no ambiente internacional relacionado à questão dos subsídios agrícolas, sendo amplamente favorável à sociedade brasileira e outros países em desenvolvimento e PMDR. Segundo o atual ministro da Agricultura do Brasil, Roberto Rodrigues, a vitória brasileira "Cria um novo padrão em comércio agrícola e abre espaço para novas negociaçôes" (Folha de São Paulo, 2004). Nessa perspectiva, a "vitória" do Brasil e seus aliados em desenvolvimento e PMDR nos contenciosos do algodão e do açúcar, de certo modo, pode ser interpretada como efeito retardado, externalidades positivas do impasse de Cancun gerado pelo G-20. Entretanto, como veremos adiante, não pode ser ainda caracterizada como uma aliança permanente, mas sim como uma coalizão que será testada na próxima Conferência da OMC. Parece-nos que a tendência será se afirmar como aliança permanente, mesmo atingindo seu objetivo central: a liberalização do comércio internacional agrícola.

\section{Considerações finais}

Como vimos, no contencioso das patentes contra os Estados Unidos na OMC, durante o governo Cardoso, foi concedida ao Brasil à possibilidade de manutenção da política pública de tratamento dos doentes de Aids. Isso significou que o protagonismo internacional brasileiro e dos seus aliados conduziu os negociadores dos Estados Unidos a optarem por retirar a queixa na $\mathrm{OMC}$, recuando na sua posição intransigente de defesa de direitos de propriedade intelectual da indústria farmacêutica norte-americana, e a negociar uma solução para o problema. Houve ganhos concretos para todos. O Brasil manteve sua política de saúde com economia de recursos. A Índia ampliou seu mercado de genéricos ao fornecer os princípios ativos para a produção de medicamentos mais baratos. Enquanto a África do Sul foi beneficiada por programas de cooperação técnica internacionais oferecidos pelo Brasil para o tratamento dos seus doentes de Aids.

Vale ressaltar ainda que houve também ganhos de aprendizado acumulado pelos países em contenciosos na OMC, permitindo, mais tarde, outros embates. Entretanto, foi apenas depois da posse do governo Lula e das mudanças de interpretação do sentido do multilateralismo na política externa brasileira que, provavelmente, emergiu um dos principais aspectos positivos dessa experiência. Uma coalizão efêmera na lógica da geometria variável de poder própria da $\mathrm{OMC}$ no governo Cardoso parece ter se transformado em uma aliança permanente - o Ibas -, durante o governo Lula, ainda que ela seja residual na questão de patentes, sem parecer oferecer grandes ganhos futuros no curto prazo. 
Já a ação do G-20 durante a V Conferência de Cancun da OMC, no bojo da Rodada Doha, com externalidades positivas representadas pelas "vitórias" no contencioso do algodão contra os Estados Unidos e do açúcar contra a UE, podem desencadear o início do fim do protecionismo agrícola dos países desenvolvidos. O significado simbólico dessa ação foi demonstrar que os países ricos não podem "mais continuar ficando na negativa absoluta nas negociações agrícolas" (Folha de São Paulo, 2004-b) em detrimento dos países em desenvolvimento e dos PMDR. Na prática, a ação do G-20 e suas externalidades positivas consolidariam jurisprudência na OMC em favor dos países em desenvolvimento (Financial Times, 2004), podendo ser expandida para produtos semelhantes, como o arroz e o trigo em prol dos interesses dos PMDR (Leo, 2004).

Como resultado, os produtores de bens agrícolas nos países em desenvolvimento e nos PMDR podem vir a ganhar maior competitividade internacional. Esta se traduziria em aumento das exportações, diminuição do desemprego e de suas conseqüências, dentre outros prováveis benefícios, os quais permitiriam aos países pobres como Benin, Chade, Mali e da ACP, os quais possuem boa parte de sua economia dependente da exportação de produtos agrícolas, recursos suficientes para o enfrentamento de graves problemas sociais.

Caso as externalidades positivas geradas pela ação do Brasil e dos seus aliados no Ibas e no G-20 não se concretizem, certamente esses países recusarão discutir novas ondas de liberalização comercial de setores que interessam os países desenvolvidos, tais como serviços, compras governamentais, propriedade intelectual, etc. Para tanto, contarão com o apoio moral da comunidade internacional e de atores importantes da sociedade civil global, o que gerará um completo impasse nas discussões sobre liberalização comercial global e nos acordos regionais, como ocorreu em Cancún, no bojo da Rodada Doha, no final de 2003.

Em suma, ao derrotar os dois maiores pilares do protecionismo e da subvenção dos países ricos contra a concorrência agrícola do mundo em desenvolvimento, o Brasil parece ter aberto o caminho para que as decisões da Rodada Doha sejam mais ambiciosas no terreno agrícola. E, certamente, ao liderar o G-20, passou a figurar entre os grandes players globais nas discussões sobre comércio internacional no século XXI.

No caso das patentes, o recuo dos Estados Unidos permitiu a flexibilização do regime internacional Trips para atender as demandas e as necessidades dos países em desenvolvimento e dos PMDR. Já o movimento do G-20 e suas externalidades positivas representadas pelas vitórias brasileiras nos contenciosos agrícolas têm sido consideradas como indutoras do início do fim dos subsídios nesse setor, abrindo possibilidades de conquista de novos mercados para as commodities brasileiras, bem como de outros países em desenvolvimento e de PMDR. Tornaram ainda os subsídios à exportação de gêneros agrícolas dos países desenvolvidos ilegais sob os termos de acordos de comércio internacional 
da OMC. Abriram a possibilidade da configuração de bens públicos globais essenciais para a defesa dos interesses da sociedade brasileira que afetam o cotidiano de cada cidadão, bem como para a comunidade internacional (Held, 2004).

Por fim, vale ressaltar que essa dinâmica interativa possibilitou a emergência de novas alianças permanentes e coalizōes de poder na política internacional entre os países em desenvolvimento e os PMDR. O primeiro caso é representado pelo Ibas - contencioso das patentes. O segundo pelo G-20 - contenciosos do algodão e do açúcar. Porém, os benefícios dessa aliança e dessa coalizão são bastante incertos no futuro, devido à ausência de poder relativo, principalmente econômico, dos seus membros para sustentar os custos da empreitada original nas discussóes sobre o papel do comércio internacional.

Isso permite-nos concluir que a manutenção e a reprodução da ação dessas alianças permanentes e, principalmente, das coalizōes nas próximas rodadas de negociações da $\mathrm{OMC}$ é incerta. A convergência só ocorreu devido à percepção de ameaça que a abertura comercial nos temas de Cingapura provoca ao mercado doméstico dos países em desenvolvimento e dos PMDR. Além disso, a capacidade dos países desenvolvidos em desmobilizar coalizões de interesses divergentes amplia-se quando eles utilizam a estratégia de barganhas cruzadas no tabuleiro comercial de geometria variável, cooptando os países menores em troca de benefícios específicos e acenando aos maiores, tais como Índia, a possibilidade de juntos ganharem em outros setores, como serviços. Portanto, a próxima reunião da OMC poderá demonstrar se as celebradas alianças permanentes advindas do diálogo Sul-Sul se transformarão ou não em coalizões residuais rumo ao desaparecimento.

Recebido em 9 de agosto de 2005 Aprovado em 9 de novembro de 2005

\section{Referências bibliográficas}

AMORIM, C. "Discurso do ministro de Estado das Relações Exteriores, embaixador Celso Amorim, por ocasiāo do Dia do Diplomata”. Brasília, 18/9/2003. Disponível em: www.mre.gov. Acessado em: 20/07/2005.

BUSH, G. W. "Presidente Bush Insiste na Cooperação do G-8 para Desenvolvimento e Comércio”. Disponível em: www.livrecomercio.embaixadaamericana.org.br/ ?action=artigo\&idartigo=419 Acessado em: 02/11/2005.

CENTER FOR RESPONSIVE POLITICS. Top Contributors: Pharmaceutical/Health Products. Disponível em: <http://www.opensecrets.org/industries/contrib.asp?Ind=H04\&Cycle=2000>. Acesso em: 26 set. 2003.

CEPALUNI, G. "O contencioso Brasil X Estados Unidos no setor farmacêutico e a licença compulsória para medicamentos contra o HIV/Aids: regimes internacionais, atores transnacionais e política doméstica”. São Paulo: Programa San Tiago Dantas - Mestrado acadêmico em relaçóes internacionais da Unesp, Unicamp e PUC/SP, 2004. 
CMI CANCÚN. "Países em desenvolvimento saíram! OMC entrou em colapso!”. 15/09/ 2003. Disponível em: <http://www.nadir.org/nadir/initiativ/agp/free/cancun/action/cancun/ 09155omc_colapso.htm>. Acessado em 20/07/2005.

FINANCIAL TIMES (Editorial). OMC concorda que subsídios para algodão são um escândalo. Financial Times, 28 de abr. 2004. Disponível em < http://noticias.uol.com.br/ midiaglobal/fintimes/ult579u1109.jhtm>. Acesso em 28.04.04.

FOLHA DE S. PAULO (Redação). Bush arma contra-ataque à vitória do Brasil. Folha de S. Paulo, São Paulo, 29 de abr. 2004-b. Disponível em <http://www1.folha.uol.com.br/fsp/ dinheiro/fi2904200436.htm>. Acesso em 29.04.04.

FOLHA DE SÃO PAULO. "Setor privado dos EUA vê Brasil nos anos 70". 13/9/2004-a.

G-20. Disponível em: http://www.g-20.mre.gov.br/ Acessado em: 20/06/2005.

GUENNIF, S. e MFUKA, C. "Brevet et Sante Dans Lês Pays em Developpement”, Centre d'Economie de l'université Paris Nord-UMR-CNRS7115, Université Paris 13, 2004. Disponível em: http://matisse.univ-paris1.fr/ID/ID040116b.pdf. Acessado em 01/08/2005.

HAAS, P. M. Introduction: Epistemic Communities and International Policy Coordination. International Organization, 46, 1-37, 1992.

HELD, D. Global Covenant: The Social Democratic alternative do the Washington Consensus. Cambridge: Ed. Polity Press, 2004.

IBAS. Disponível em: http://www.mre.gov.br/portugues/politica_externa/grupos/ibas/ index.asp Acessado em 20/06/20005.

ICONE. "A política comercial brasileira e as negociaçōes internacionais". Disponível em: <http:/ /www.iconebrasil.org.br/Apresentações/OCB_Goiania_Jank_Jun05(res).pdf> Acessado em: 09/04/2005.

INDIA INFOLINE NEWS. "India didn't yield to any pressure: Jaitley". 15/09/2003. Disponível em: <http://www.indiainfoline.com/news/news.asp?dat=26409>. Acessado em: 20/07/2005.

LEO, S. e LANDIM, R. Decisão da OMC não encerra caso do algodão. Valor Econômico, São Paulo, 15 de jun. 2004. Brasil, p. A5.

LOVE, J. "Notes on the USTR Watch Lists and Reports", 1999. Disponível em: <http:// www.cptech.org/ip/health/whatrlists.html>. Acessado em: 20/07/2005.

LULA, L. I. "Discurso proferido no Fórum da Sociedade Civil durante a UNCTAD XI". São Paulo,15/06/2004. Disponível em: < http://www.forumsociedadecivil.org.br/ dspMostraNoticia.asp? idNews=68> Acessado em 27/06/2005.

O ESTADO DE S. PAULO. “Comunicação truncada”. O Estado de S. Paulo, São Paulo, 4 de julho de 2004. Disponível em <http://www.estadao.com.br/ecolunistas/sonia/04/07/ sonia040705.htm>. Acesso em 27.07.2004.

O ESTADO DE SÃO PAULO. “Senador dos EUA: Brasil levou Cancún ao fracasso”. 18/9/2003.

OXFAM GB. Drug Companies vs. Brazil: The Threat to Public Health. Oxford. Disponível em: <http://www.oxfam.org.uk/what_we_do/issues/health/drugcomp_brazil.htm>. Acesso em: 26 set. 2003.

REDIFF.COM “CII, Ficci laud role of developing countries at Cancun”. 15/09/2003. Disponível em: http://in.rediff.com/money/2003/sep/15wto6.htm. Acessado em 20/07/2005.

ROFFE, P. "Nota sobre direitos de propriedade intelectual e saúde pública”. In: Política Externa, vol. 12, no 3. São Paulo: Paz e Terra, 2004. 
ROSENBERG, T. "How to Solve the World's Aids Crises: Look at Brazil”, In: The New York Times Magazine, 28 de Janeiro de 2001.

SARAIVA, J. F. S. “O Brasil e o Conselho de Segurança das Nações Unidas”. Colunas de RelNet, no 11, mês 1-6, 2005. Disponível em: http: <//www.relnet.com.br/cgi bin/ WebObjects/RelNet.woa/1/wo/Bpx5I94b8rQh9AVYVjDzVM/2.17.1.0.0.3.2.5> Acessado em: 20/06/2005.

VEIGA, P. da M. "A política comercial do governo Lula". In: Revista Brasileira de Comércio Exterior, Ano XIX, Abril/Junho de 2005.

VELASCO E CRUZ, S. C. "Estado e mercado: a OMC e a constituição (incerta) de uma ordem econômica global”. Revista Brasileira de Ciências Sociais, fev. 2005, vol.20, no 57, p.83-108.

VIGEVANI, T; OLIVEIRA, M. F. "Política externa no governo FHC: a busca de autonomia pela integração". In: Tempo Social, volume 15, no 2, 2003.

WAYNE, E. A. "A MCA promove políticas econômicas sólidas”. Disponível em: <http:// usinfo.state.gov/journals/ites/0303/ijep/wayne.htm> Acessado em: 02/11/2005.

ZOELICK, R. “The United States will not wait”, Financial Times, 22-09-2003.

\section{Resumo}

O objetivo deste artigo é demonstrar que o protagonismo internacional do governo Lula busca ressuscitar a questão do desenvolvimento tendo como base tanto o regionalismo, quanto a recuperação da clivagem Norte/Sul na política internacional em benefício das novas demandas dos países em desenvolvimento. Baseado nessa constatação, indagamos se as estratégias internacionais e o diálogo Sul-Sul presente na retórica e na ação da política externa do governo Lula representam alianças duradouras ou coalizões efêmeras nas relações internacionais contemporâneas entre os países em desenvolvimento e menor desenvolvidos.

\section{Abstract}

The objective of the article is to demonstrate that the international protagonism of Lula's government seeks to bring back to international politics the development issue based, on one hand, on regionalism, and on the North / South clivage on the other hand, in order to advance the new demands of developing coutries. It is aked, based on this assumption, if the international strategies and the South-South dialogue both present on retoric and actions of Lula's government foreign policy represent enduring alliances or ephemeral coalitions among developing and least developing countries.

Palavras-chave: Política Externa do Governo Lula; Relações Sul-Sul; Alianças e Coalizões Internacionais; Ibas; G-20.

Key words: Lula's Foreing Policy; South-South Relations; International Alliance and Coalitions; Ibsa; G-20. 